\title{
Use of deferasirox, an iron chelator, to overcome imatinib resistance of chronic myeloid leukemia cells
}

\author{
Dae Sik Kim ${ }^{1}$, Yoo Jin $\mathrm{Na}^{2}$, Myoung Hee Kang ${ }^{2}$, Soo-Young Yoon ${ }^{3}$, and Chul Won Choi ${ }^{1}$
}

${ }^{1}$ Division of Hematology and Oncology, Department of Internal Medicine, Korea University School of Medicine, Seoul; ${ }^{2}$ Graduate School of Medicine, Korea University School of Medicine, Seoul; ' ${ }^{2}$ Department of Laboratory Medicine, Korea University School of Medicine, Seoul, Korea

Received: February 2, 2015

Revised : March 18, 2015

Accepted: March 30, 2015

\section{Correspondence to}

Chul Won Choi, M.D.

Division of Hematology and Oncology, Department of Internal Medicine, Korea University Guro Hospital, 148 Gurodong-ro, Guro-gu, Seoul 08308, Korea

Tel: +82-2-2626-3058

Fax: +82-2-862-6453

E-mail: bonnie@korea.ac.kr
Background/Aims: The treatment of chronic myeloid leukemia (CML) has achieved impressive success since the development of the Bcr-Abl tyrosine kinase inhibitor, imatinib mesylate. Nevertheless, resistance to imatinib has been observed, and a substantial number of patients need alternative treatment strategies. Methods: We have evaluated the effects of deferasirox, an orally active iron chelator, and imatinib on $\mathrm{K}_{5} 62$ and KU812 human CML cell lines. Imatinib-resistant CML cell lines were created by exposing cells to gradually increasing concentrations of imatinib.

Results: Co-treatment of cells with deferasirox and imatinib induced a synergistic dose-dependent inhibition of proliferation of both CML cell lines. Cell cycle analysis showed an accumulation of cells in the subGi phase. Western blot analysis of apoptotic proteins showed that co-treatment with deferasirox and imatinib induced an increased expression of apoptotic proteins. These tendencies were clearly identified in imatinib-resistant CML cell lines. The results also showed that co-treatment with deferasirox and imatinib reduced the expression of Bcr-

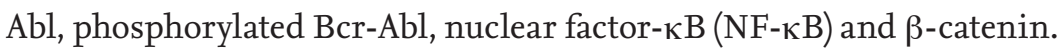

Conclusions: We observed synergistic effects of deferasirox and imatinib on both imatinib-resistant and imatinib-sensitive cell lines. These effects were due to induction of apoptosis and cell cycle arrest by down-regulated expression of NF- $\mathrm{KB}$ and $\beta$-catenin levels. Based on these results, we suggest that a combination treatment of deferasirox and imatinib could be considered as an alternative treatment option for imatinib-resistant CML.

Keywords: Deferasirox; Iron chelator; Chronic myeloid leukemia; Imatinib; Resistance

\section{INTRODUCTION}

Chronic myeloid leukemia (CML) is a myeloproliferative neoplasm characterized by the clonal expansion of hematopoietic stem cells with a reciprocal translocation between chromosomes 9 and 22. This Bcr-Abl fusion gene is transcribed into a chimeric Bcr-Abl mRNA, re- sulting in activation of tyrosine kinase and down-stream kinases that prevent apoptosis [1]. Until the development of Bcr-Abl tyrosine kinase inhibitors (TKIs), patients with CML such as patients with acute leukemia, had poor prognosis, and the only treatment strategy for cure was stem cell transplantation. However, CML treatment has shown impressive success with the development of 
Bcr-Abl TKIs. Imatinib mesylate was the first Bcr-Abl TKI to be developed for the treatment of CML [2-4]. In long-term follow up data from the IRIS (International Randomized Study of Interferon and STI571) trial, the major molecular response rate and overall survival rates were $86 \%$ and $85 \%$, respectively, after 8 years [5].

Despite high response rates, resistance to TKIs develops in a significant number of CML patients $[6,7]$. Various strategies have been investigated to overcome this resistance, including increasing the dose of imatinib, developing novel drugs that act on the mutated adenosine triphosphate (ATP)-binding sites of the Bcr-Abl fusion protein, and combining imatinib with other drugs to block the down-stream signals of the Bcr-Abl protein $[7,8]$. Recently, second generation TKIs (nilotinib and dasatinib) have been developed to overcome imatinib resistance $[9,10]$. Although these agents have shown superior outcomes to imatinib, some resistances, such as the T315I mutation, have not been overcome. Furthermore, some patients cannot be treated with a TKI alone. Those patients must be treated by stem cell transplantation, which has a high treatment-related mortality rate. For these reasons, development of new strategies for eradication of resistant CML cells is needed.

The Bcr-Abl oncogenic pathway is the main causative factor in leukemogenesis of CML. Other signaling molecules reported to be involved in the pathogenesis of CML include the phosphoinositide 3-kinase/Akt/mammalian target of rapamycin (mTOR) pathway, the RAS/mitogen-activated protein kinase pathway, the Janus-activated kinase/signal transducer and activator of transcription (JAK/STAT) pathway, the Hedgehog pathway, and the Wnt pathway [11]. Considerable research on inhibitors of these pathways is being carried out. It has been reported that iron overload may lead to proliferation of several types of cancer. Our institute previously reported the effects of iron chelator on lymphoma and leukemia cells $[12,13]$. Furthermore, cancer cells typically require more iron than normal cells to mediate their rapid DNA synthesis and growth $[14,15]$. Treatment of hepatocellular carcinoma or acute leukemic cancer cells with an iron chelator inhibited proliferation and induced apoptosis [16]. The orally administered iron chelator, deferasirox, is a widely used drug for the treatment of iron overload, which is caused by repetitive transfusion in patients with hematologic malignancies. Recently pub- lished prospective trials have revealed that deferasirox leads to hematologic improvement in patients with myelodysplastic syndrome [17]. A case report showed that deferasirox administration led to a complete remission in a patient with chemotherapy-refractory acute monocytic leukemia [18]. These anticancer effects could be explained by the down-regulation of the NF- $\mathrm{B}, \mathrm{mTOR}$, and/or Wnt pathways by deferasirox [19,20]. Thus, an anti-leukemic effect of deferasirox may be expected in CML patients. Such an antileukemic effect would also be expected in imatinib-resistant CML cells by blocking another pathway down-stream of the Bcr-Abl signaling pathway $[19,21,22]$. The aim of this study was to identify the synergistic effects of deferasirox and imatinib and to confirm the effect of this combination treatment on imatinib-resistant cells.

\section{METHODS}

\section{Cell lines}

This study was conducted with the human CML cell lines $\mathrm{K}_{5} 62$ and KU812. The $\mathrm{K}_{5} 62$ cell line was purchased from the Korea Cell Line Bank (KCLB, Seoul, Korea), and the KU812 cell line was obtained from the American Type Culture Collection (ATCC, Manassas, VA, USA). The cells were maintained according to instructions provided by the ATCC and KCLB. Both cell lines were maintained in Roswell Park Memorial Institute Media 1640 (RPMI-1640) supplemented with 10\% fetal bovine serum and antibiotic-antimycotic (100x, Life Technologies, Waltham, MA, USA) at $37^{\circ} \mathrm{C}$ and $5 \% \mathrm{CO}_{2}$ in a humidified incubator.

\section{Drugs and reagents}

The oral iron chelator deferasirox was provided by Novartis (Basel, Switzerland), and imatinib mesylate was purchased from Sigma-Aldrich (St. Louis, MO, USA). Primary antibodies were purchased from Cell Signaling Technology (Beverly, MA, USA; anti-BCR-ABL, anti-pBcr-Abl, anti-Akt, anti-caspase 3/9, anti-poly [ADP-ribose] polymerase [PARP], anti-STAT3, anti-pSTAT3, anti-pIk$\mathrm{Ba}$, and anti-poly-glycogen synthase kinase 3 [pGSK 3$]$ $\alpha / \beta)$, BD Biosciences (Franklin Lakes, NJ, USA; anti-Bax and anti- $\beta$-actin), Santa Cruz (Santa Cruz, CA, USA; anti-IkBa), and Sigma (anti-NF-кB). 


\section{Cell viability assay}

Cell viability was evaluated by a colorimetric assay (Ez-cytox Kit, High Sensitive Water Soluble Tetrazolium). K562 and KU812 CML cells were seeded in 96-well plates $\left(1.5 \times 10^{4}\right.$ cells/well $)$ and were treated with various concentrations of deferasirox $(10,20,50$, and $100 \mu \mathrm{M})$ or imatinib $(0.5,1,5,10,20,50$, and $100 \mu \mathrm{M})$. After 24,48 , or 72 hours of incubation, $10 \mu \mathrm{L}$ per well of the Kit reagent was added to each well. The cells were then incubated at $37^{\circ} \mathrm{C}$ for an additional 4 hours. The absorbance of the treated cells at $450 \mathrm{~nm}$ was measured by using a microtiter plate reader. The combined effects of deferasirox and imatinib (D/I: 10/1, 10/5, 10/10, 20/1, 20/5, or $20 / 10 \mu \mathrm{M}$ ) were evaluated by the same method. The synergistic effect of deferasirox and imatinib was determined by calculating the combination index (CI) by using Calcusyn Software (Biosoft, Ferguson, MO, USA) [23,24]. A value of $\mathrm{CI}<1$ indicates synergism, $\mathrm{CI}=1$ indicates an additive effect, and CI $>1$ reflects an antagonist interaction.

\section{Cell cycle analysis}

$\mathrm{K}_{5} 62$ and KU812 cells were plated in 6-well plates with RPMI media and treated with deferasirox $(10,20,50$, and $100 \mu \mathrm{M})$ or imatinib $(0.5,1,5,10,20,50$, and 100 $\mu \mathrm{M})$ alone or in combination (D/I: 10/1, 10/5, 10/10, 20/1, $20 / 5$, or $20 / 10 \mu \mathrm{M}$ ). After treatment, cells were harvested at designated times and washed twice with phosphate buffered saline (PBS). Cells were fixed in PBS containing $5 \mathrm{mM}$ ethylenediaminetetraacetic acid and $85 \%$ ethanol for 30 minutes at $4^{\circ} \mathrm{C}$. The cells were then treated with $20 \mu \mathrm{g} / \mathrm{mL}$ RNase A and $50 \mu \mathrm{g} / \mathrm{mL}$ propidium iodide (Sigma) for 30 minutes and analyzed with a Cytomix FC 500 (Beckman Coulter, Brea, CA, USA) flow cytometer. Ten thousand events were counted per sample. The percentages of the cell population at the $\mathrm{G}^{\circ}-\mathrm{G}^{1}$ and $\mathrm{G}^{1}$ phases were calculated.

\section{Apoptosis analysis}

CML cells treated with deferasirox (10, 20, 50, and 100 $\mu \mathrm{M})$ or imatinib $(0.5,1,5,10,20,50$, and $100 \mu \mathrm{M})$ alone or in combination (D/I: $10 / 1,10 / 5,10 / 10,20 / 1,20 / 5$, or $20 / 10$ $\mu \mathrm{M})$ were evaluated by annexin $\mathrm{V} /$ propidium iodide staining and flow cytometry.

\section{Western blot analysis}

To evaluate the mechanisms of apoptosis after treat- ment of CML cells with deferasirox and imatinib, we performed western blot analyses. Whole cell extraction was conducted by using RIPA buffer (50 mM Tris, 150 $\mathrm{mM} \mathrm{NaCl}, 1 \%$ Triton X-100, $0.1 \%$ sodium dodecyl sulfate, and $1 \%$ sodium deoxycholate $\mathrm{pH}$ 7.4) supplemented with protease inhibitors ( $1 \mathrm{mM}$ phenylmethylsulfonyl fluoride, $10 \mu \mathrm{g} / \mathrm{mL}$ peptasin $\mathrm{A}, 10 \mu \mathrm{g} / \mathrm{mL}$ aprotinin, and $5 \mu \mathrm{g} / \mathrm{mL}$ leupeptin). The protein concentrations were measured by using Bio-Rad protein assay kits (Bio-Rad, Hercules, CA, USA). The protein lysates were resolved by sodium docdecyl sulfate polyacrylamide gel electrophoresis, then transferred onto nitrocellulose membranes (HybondTM-P, Amersham Biosciences Co., Piscataway, NJ, USA), blocked with PBS containing $0.2 \%$ Tween 20 and $5 \%$ non-fat dry milk, and incubated with primary antibody. The primary antibodies against the following proteins: Bcr-Abl, pBcr-Abl, Bax, caspase 3, caspase 9, PARP, STAT3, pSTAT3, IkB $\alpha$, pIkB $\alpha$ and NF-кB, pGSK3 $\alpha / \beta, \beta$-catenin, and $\beta$-actin.

\section{Imatinib-resistant cell line}

Imatinib-resistant CML cell lines (K562R, KU812R) were induced by continuous exposure to imatinib in stepwise increments from $0.5 \mathrm{nM}$ to $1 \mu \mathrm{M}$ after every 10 days of culture. Viable imatinib-resistant CML cells were maintained in $1 \mu \mathrm{M}$ imatinib. To confirm the resistance of the cells, imatinib-sensitive cells (K562 and KU812) and imatinib-resistant cells (K562R and KU812R) were compared by using the cell viability assay and Western blot analysis. To determine the effect of co-treatment in imatinib-resistant cells, the induction of apoptosis and the expression level of Bcr-Abl protein and down-strea $\mathrm{m}$ signaling molecules were evaluated by western blot.

\section{Statistical analysis}

Data analysis was performed by using the IBM SPSS version 21 (IBM Co., Armonk, NY, USA). Differences among treated cell line groups were compared by the Student $t$ test and the chi-square test. A $p$ value of less than 0.05 was considered statistically significant.

\section{RESULTS}

\section{Co-treatment with deferasirox and imatinib inhibits proliferation of human CML cells}



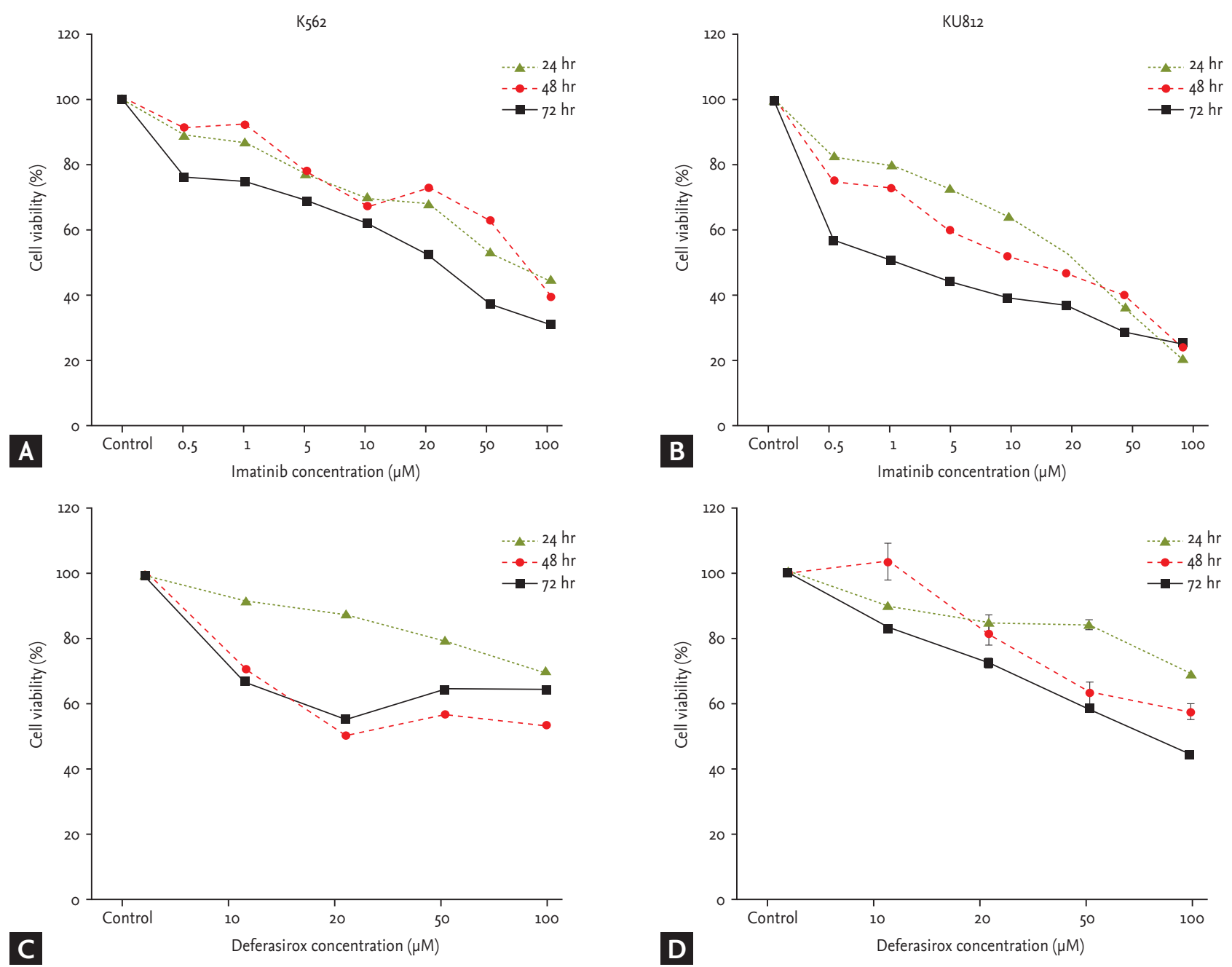

Figure 1. Cell viability analysis of deferasirox or imatinib single treatment. (A) Cell viability of $\mathrm{K}_{5} 62$ cells after treatment with imatinib alone. (B) Cell viability of KU812 cells after treatment with imatinib alone. (C) Cell viability of K562 cells after treatment with deferasirox alone. (D) Cell viability of KU812 cells after treatment with deferasirox alone.

Imatinib and deferasirox both produced a dose- and time-dependent reduction of cell viability of both $\mathrm{K}_{5} 62$ and KU812 cells (Fig. 1). After co-treatment of KU812 cells with deferasirox $20 \mu \mathrm{M}$ and imatinib $10 \mu \mathrm{M}$, cell viability was reduced to $33.7 \%$, whereas treatment with deferasirox $20 \mu \mathrm{M}$ or imatinib $10 \mu \mathrm{M}$ alone reduced the cell viability to only $80.2 \%$ and $66.5 \%$, respectively (Fig. 2A). This trend was similar for $\mathrm{K}_{5} 62$ cells (Fig. $2 \mathrm{~B}$ ). To determine whether there was a synergistic effect of the two drugs, we analyzed the results by the Chou and Talalay [23] method, which is the most widely used method to determine the effects of drug combinations. The CI values for deferasirox and imatinib at all of the combination concentrations were all less than 1 (CI, o.18 to
0.67). This shows that co-treatment with these two drugs produces synergism.

\section{Co-treatment with deferasirox and imatinib induces cell cycle arrest at the subGi phase}

To determine the effects of deferasirox and imatinib on cell cycle progression, both CML cell lines were treated with each drug and analyzed by flow cytometry. Treatment with deferasirox or imatinib singly induced an accumulation of cells in the subGi phase for both the cell lines (Fig. 3). Co-treatment with both drugs led to a greater cell accumulation in the subGi phase than single treatment. Cells in S phase were decreased. 

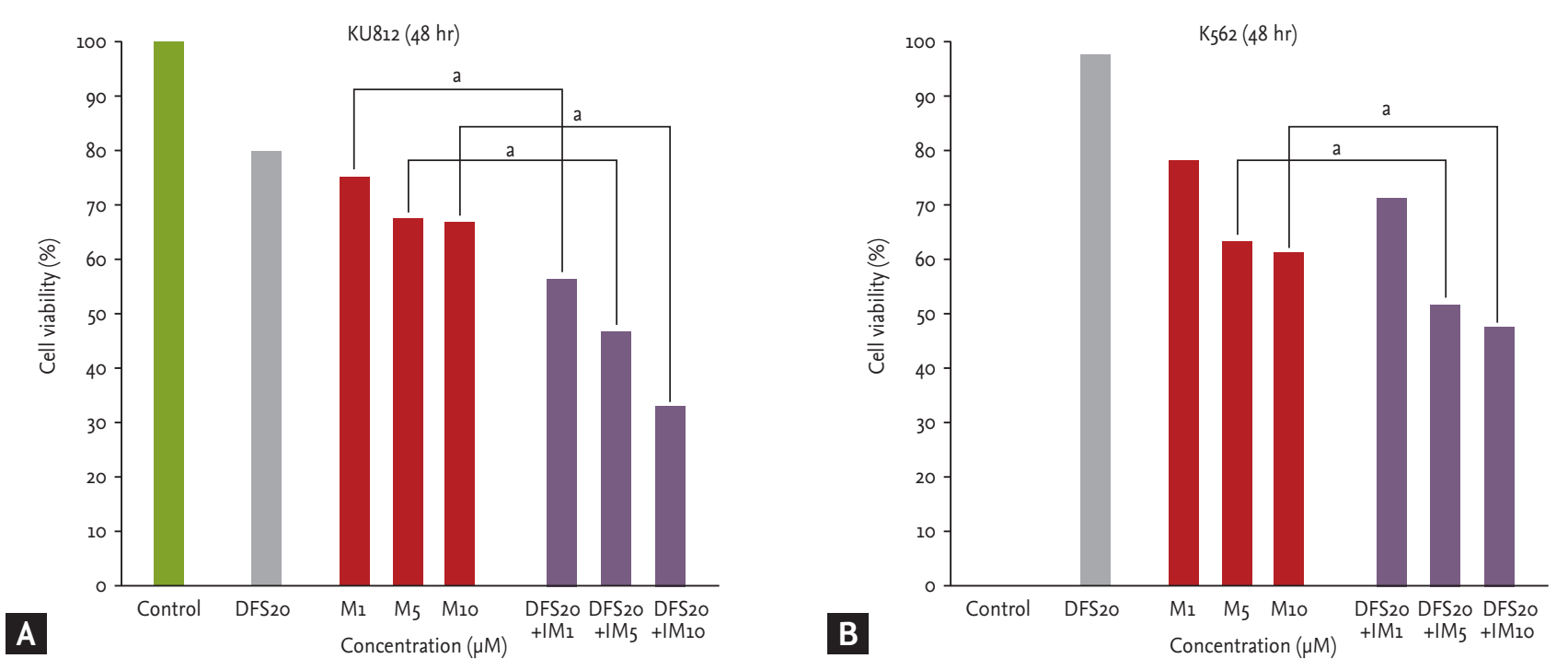

Figure 2. Cell viability analysis of co-treatment with deferasirox and imatinib. Co-treatment with deferasirox and imatinib induced a synergistic dose-dependent inhibition of proliferation of (A) KU812 cells and (B) K562 cells. The confidence interval value of deferasirox and imatinib for all of the combination concentrations was less than 1. Con, control; DFS, deferasirox; IM, imatinib. ${ }^{\mathrm{a}} \mathrm{p}<0.001$.
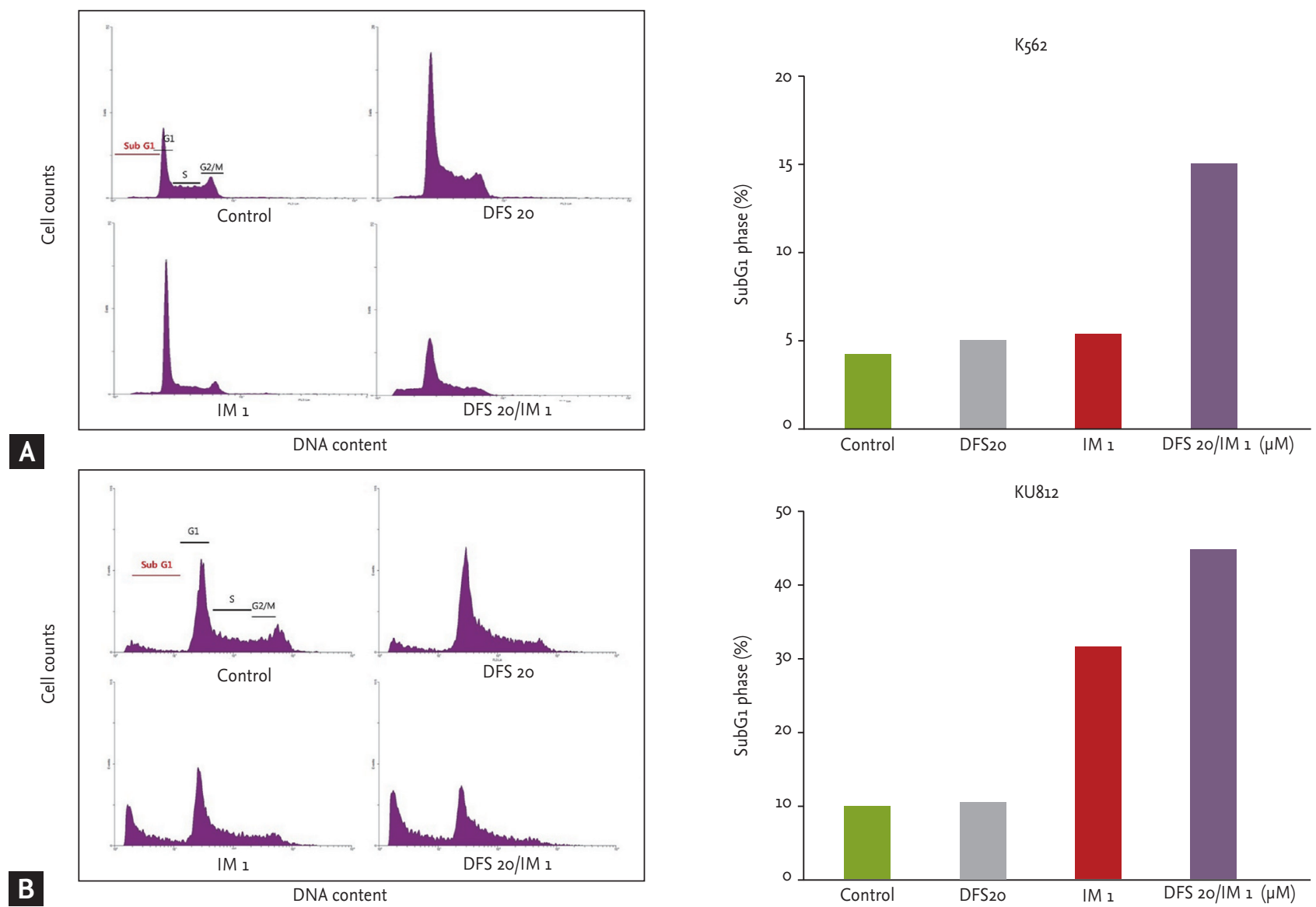

Figure 3. Cell cycle analysis of co-treatment with deferasirox and imatinib. Co-treatment with two drugs increased cell accumulation in the subG1 phase and decreased S phase cells for both (A) K562 cells and (B) KU812 cells. DFS, deferasirox; IM, imatinib. 


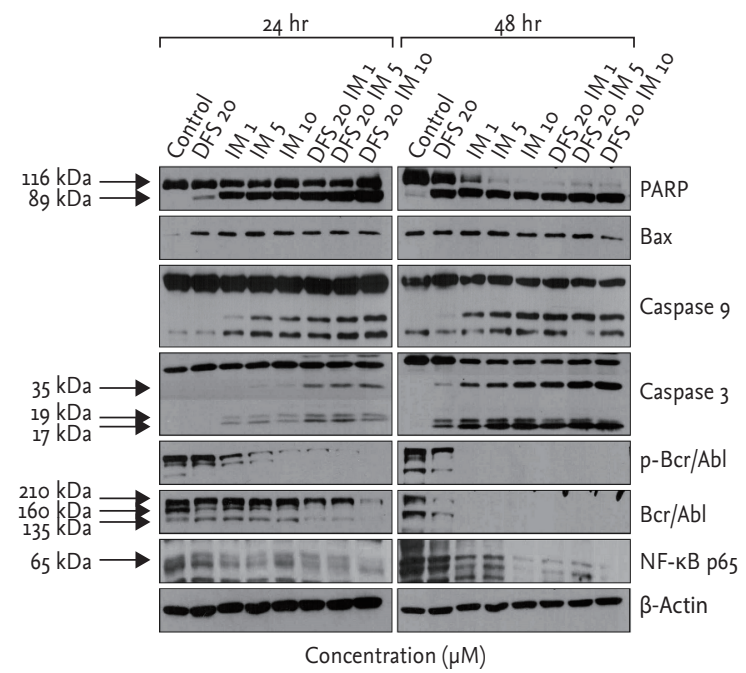

Figure 4. Western blot analysis of co-treatment with deferasirox and imatinib in $\mathrm{K}_{5} 62$ cells. Compared to single drug treatment, co-treatment with deferasirox and imatinib increased expressions of cleaved poly ADP-ribose polymerase (PARP) and cleaved caspases 3 and 9, which are the markers of apoptosis. Co-treatment led to decreased expression of

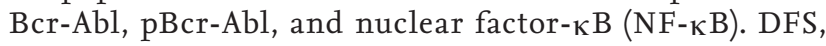
deferasirox; IM, imatinib.
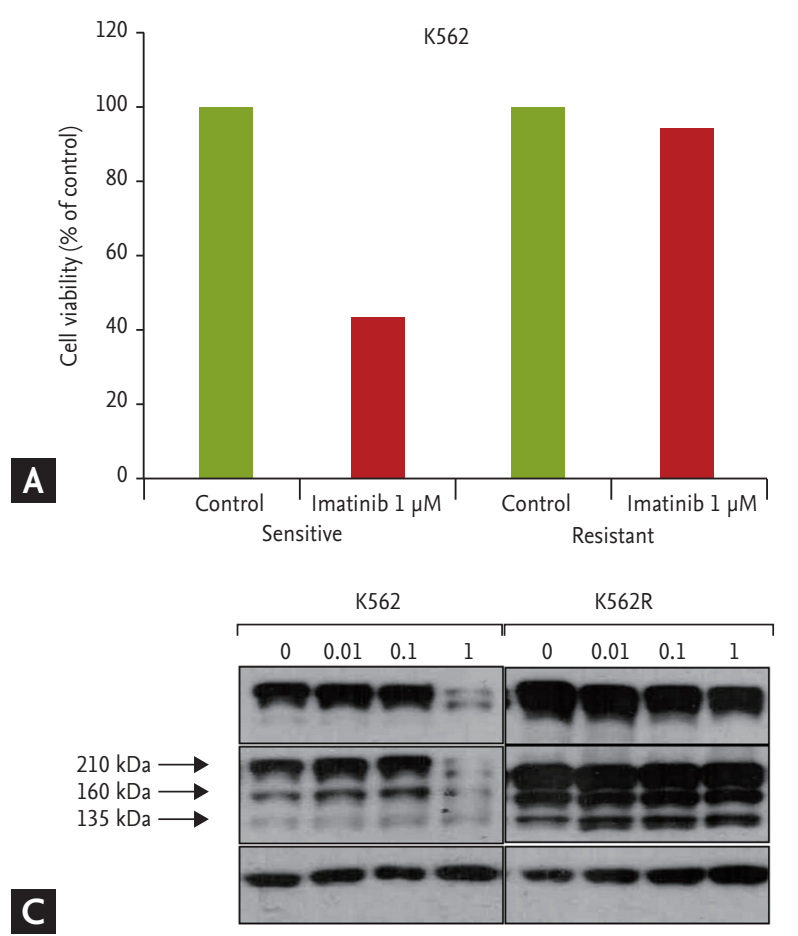

\section{Co-treatment with deferasirox and imatinib induces apoptosis and significantly down-regulates the Bcr- Abl down-stream pathway of human CML cells}

To determine the effects of deferasirox on apoptosis and protein expression after treatment with deferasirox or imatinib, singly or in combination, we measured the expression levels of proteins by using Western blot analysis. Compared to single treatment, the results of co-treatment with deferasirox and imatinib showed increased expression of cleaved PARP and cleaved caspase 3/9 as markers of apoptosis. Expressions of Bcr-Abl, pBcr-Abl, and NF- $\mathrm{KB}$ of $\mathrm{K}_{5} 62$ cells were decreased after the combination treatment (Fig. 4). Similar results were obtained with KU812 cells.

\section{Co-treatment with deferasirox and imatinib induced apoptosis in imatinib-resistant CML cells}

Imatinib-resistant CML cell lines were produced by repeated exposure to gradually increasing concentrations of imatinib, from 0.01 to $1 \mu \mathrm{M}$. After treatment with imatinib, cell viabilities were compared between imatinib-sensitive and resistant cell lines by colorimetric
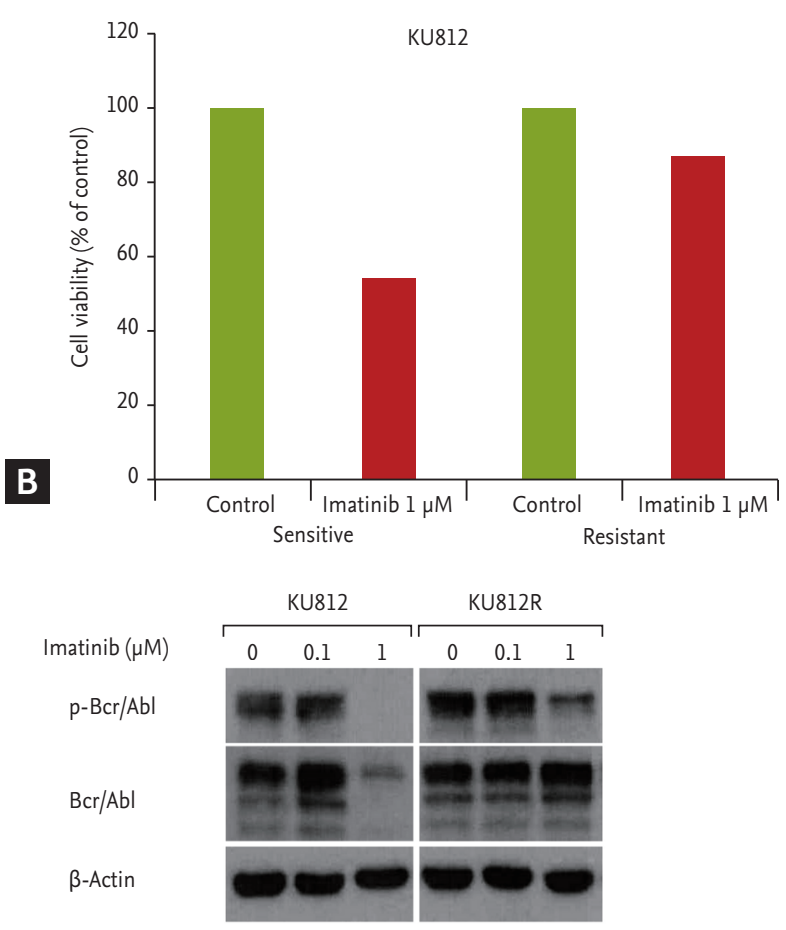

Figure 5. Confirmation of imatinib resistance in imatinib-resistant chronic myeloid leukemia (CML) cells. After treatment with $1 \mu \mathrm{M}$ imatinib, the viability of $\mathrm{K}_{5} 62$ cells was decreased nearly in half. (A) However, there was little change in the viability of imatinib-resistant K562 cells. (B) Similar results were demonstrated with KU812 cells. (C) The expression of Bcr-Abl and pB$\mathrm{cr}-\mathrm{Abl}$ in imatinib sensitive CML cells (K562 and KU821) were decreased with imatinib treatment, but there were no changes in the expression of Bcr-Abl and pBcr-Abl in imatinib-resistant chronic myeloid leukemia cells (K562R and KU812R). 


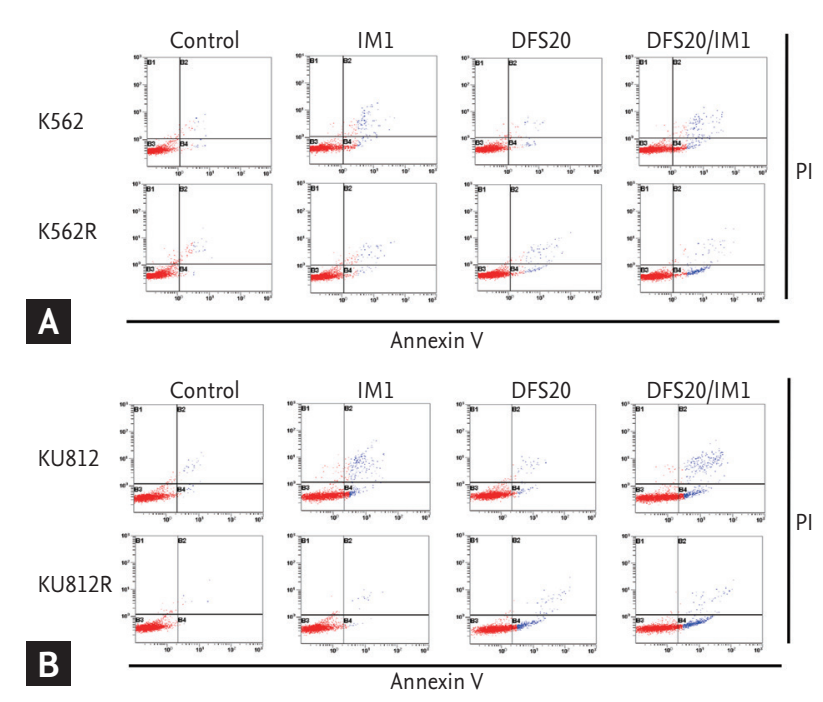

Figure 6. Apoptosis analysis by flow cytometry. The fraction of early apoptosis (annexin V+/PI-) was not increased with imatinib or deferasirox alone, but the percentage of annexin $\mathrm{V}+/ \mathrm{PI}-$ cells was increased significantly after co-treatment in imatinib-resistant (A) K562 and (B) KU812 cells. DFS, deferasirox; IM, imatinib.

assay. Only $43 \%$ of $\mathrm{K}_{5} 62$ cells survived, but $95 \%$ of imatinib-resistant $\mathrm{K}_{5} 6_{2}\left(\mathrm{~K}_{5} 62 \mathrm{R}\right)$ cells survived after treatment with $1 \mu \mathrm{M}$ imatinib (Fig. 5A). For KU812 cells, 52\% survived after $1 \mu \mathrm{M}$ of imatinib, but $90 \%$ of imatinib-resistant KU812 (KU812R) cells survived (Fig. 5B). The expression levels of Bcr-Abl and pBcr-Abl in $\mathrm{K}_{5} \mathrm{G}_{2}$ and KU812 cells were decreased with imatinib treatment, but there was no change in that of $\mathrm{Bcr}-\mathrm{Abl}$ and $\mathrm{pBcr}-\mathrm{Abl}$ in imatinib-resistant K562R and KU812R cells (Fig. 5C).

To determine whether the cytotoxic effect of co-treatment with deferasirox and imatinib was associated with the induction of apoptosis, we measured the fraction of cells in early apoptosis (annexin V+/PI-) by flow cytometry. The percentage of annexin $\mathrm{V}+/ \mathrm{PI}-$ cells did not increase with imatinib or deferasirox single treatment, but the percentage of annexin V+/PI- cells increased significantly after combined treatment for both imatinib-resistant cell lines (Fig. 6).

\section{Co-treatment with deferasirox and imatinib signifi- cantly down-regulates Bcr-Abl and down-stream pathways of human CML cells}

Lastly, to determine the signaling pathways affected by co-treatment with deferasirox and imatinib in imatinib-resistant CML cells, the expression levels of Bcr-Abl and down-stream signaling pathways were evaluated by

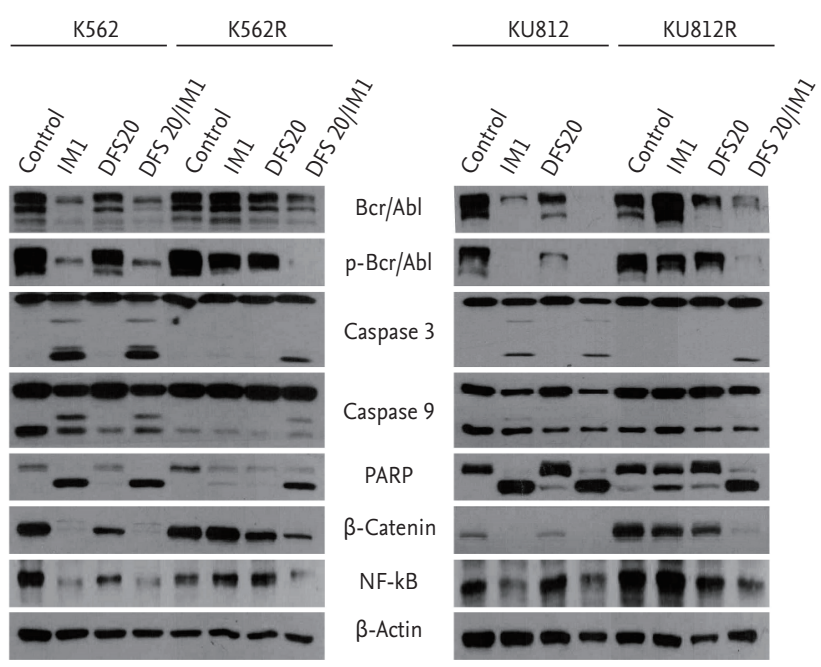

Figure 7. Effects of co-treatment with deferasirox and imatinib on the Bcr-Abl signaling pathway in imatinib-sensitive (K562 and KU812) and resistant (K562R and KU812R) cells. The expression level of cleaved poly ADP-ribose polymerase (PARP), cleaved caspase 3, and cleaved caspase 9 were increased after co-treatment in $\mathrm{K}_{5} 62 \mathrm{R}$ and KU812R cells. The expression level of cleaved PARP, cleaved caspase 3, and cleaved caspase 9 of $\mathrm{K}_{5} 62$ and KU812 cells was increased by imatinib only treatment, but the expression levels in $\mathrm{K}_{5} 62 \mathrm{R}$ and KU812R cells were not affected. The levels of nuclear factor- $\kappa \mathrm{B}(\mathrm{NF}-\kappa \mathrm{B})$ and $\beta$-catenin were down-regulated by co-treatment of imatinib-resistant CML cells. DFS, deferasirox; IM, imatinib.

Western blot analysis. As found with imatinib-sensitive cells, the expression levels of cleaved PARP and cleaved caspase 3/9 were increased after co-treatment in imatinib-resistant CML cells. However, the expression level of cleaved PARP and cleaved caspase 3/9 did not increase with imatinib single treatment in imatinib-resistant cells, in contrast to the results with imatinib-sensitive cells. As shown in Fig. 7, the levels of NF- $\kappa B$ and $\beta$-catenin were down-regulated by co-treatment of imatinib-resistant CML cells. However, the Western blot results indicated that imatinib single treatment did not decrease the level of NF- $\mathrm{KB}$ and $\beta$-catenin in imatinib-resistant CML cells.

\section{DISCUSSION}

This study provides an analysis of the synergistic effects of the iron chelator deferasirox and the Bcr-Abl TKI, imatinib on imatinib-resistant CML cells. Co-treatment with deferasirox and imatinib had synergistic effects on 
not only imatinib-sensitive cells but also imatinib-resistant cells. Co-treatment inhibited cell proliferation and induced accumulation of cells in the subGi phase. Induction of apoptosis was confirmed by Western blot and flow cytometry analyses. The results of the Western blot assay showed that co-treatment with deferasirox and imatinib reduced the expression levels of Bcr-Abl, pBcr-Abl, NF- $\kappa B$, and $\beta$-catenin in imatinib-resistant cells.

To overcome imatinib resistance, novel ATP-competitive small molecule TKIs, dasatinib and nilotinib, have been developed $[9,10]$. These drugs have shown efficacy in almost all CML patients. However, some Bcr-Abl mutations such as the $\mathrm{T}_{315} \mathrm{I}$ mutation, remain resistant to these drugs. In addition, there are other causes of imatinib resistance. Thus, the development of alternative treatments is needed, and it is necessary to identify agents that specifically target the pathways down-stream of the Bcr-Abl signaling pathway to treat CML. Deferasirox is a widely used orally administered iron chelator, which is used to reduce iron overload in patients with hematologic disease. One of the advantages of deferasirox is that it is easy to take and is well tolerated, unlike other iron chelators. Because several studies have reported the antitumor and iron chelating effects of deferasirox against solid tumors and leukemia cells, a synergistic effect is expected when deferasirox is used in combination with other anticancer agents $[16,19]$. We revealed the antitumor effect of the combined treatment of deferasirox and imatinib in CML cells, and this effect was confirmed to be a synergistic effect by the Chou and Talalay [23] method.

Constitutive NF- $\mathrm{KB}$ activation has been demonstrated in hematologic malignancies $[25,26]$. Moreover, NF- $\mathrm{KB}$ has been identified as a down-stream component of the $\mathrm{Bcr}-\mathrm{Abl}$ initiated signaling pathway that is necessary for bone marrow cell transformation and leukemogenesis in CML [27]. The role of deferasirox as a NF- $\mathrm{KB}$ inhibitor has been reported in several previous studies [19,21]. In our study, the expression level of NF- $\mathrm{kB}$ (p65) was downregulated by co-treatment with deferasirox and imatinib. This effect was also observed in imatinib-resistant cells. It has been reported that the blockade of NF-kB signaling pathway could overcome imatinib-resistance, a finding that is consistent with the results of our study [28-30].

After treatment with imatinib, some residual leuke- mic cells, most likely leukemic stem cells (LSCs), are resistant to imatinib treatment. The inhibition of Bcr-Abl kinase activity alone is insufficient to eradicate LSCs [31]. The Wnt/ $\beta$-catenin signaling pathway plays an important role in the survival and self-renewal of imatinib-resistant LSCs and has been linked to many cancers [32]. $\beta$-Catenin is also stabilized by the Bcr-Abl protein and is involved in Bcr-Abl leukemogenesis [33]. Our results showed that the baseline level of $\beta$-catenin in imatinib-resistant CML cells was increased as compared with imatinib-sensitive CML cells. This means that a number of imatinib-resistant CML cells are LSCs. Treatment with deferasirox and imatinib in combination resulted in depletion of Bcr-Abl and pBcr-Abl and down-regulation of $\beta$-catenin, whereas imatinib alone did not affect $\mathrm{Bcr}-\mathrm{Abl}$ and $\beta$-catenin levels in imatinib-resistant $\mathrm{CML}$ cells. These observations indicate that co-treatment can eradicate imatinib-resistant CML cells by depleting Bcr$\mathrm{Abl}$ and $\beta$-catenin, thereby disrupting the $\mathrm{Bcr}-\mathrm{Abl} / \beta$-catenin axis that is essential for LSC survival and self-renewal.

The results of this study are derived from experiments with cell lines in vitro. Animal experiments should be undertaken to confirm these results in vivo. There are still some challenges regarding the clinical applications of deferasirox and imatinib because of side effects, such as gastrointestinal distress; these side effects might be the determining factor for drug dosing and/or compliance. However, it is worth noting that deferasirox showed antileukemic effects against imatinib-resistant CML cells and the synergistic effect occurred with a combination of easily accessible drugs, rather than with cytotoxic chemotherapeutic agents. Based on this study, we suggest that a combination treatment of deferasirox and imatinib may be a suitable alternative treatment option for imatinib-resistant CML.

\section{KEY MESSAGE}

1. Co-treatment of deferasirox and imatinib showed anti-leukemic effects against both imatinib-sensitive and imatinib-resistant chronic myeloid leukemia cells.

2. Anti-leukemic effects of deferasirox are due to induction of apoptosis and cell cycle arrest by down-regulated expression of nuclear factor $-\kappa B$ and $\beta$-catenin levels. 


\section{Conflict of interest}

No potential conflict of interest relevant to this article was reported.

\section{Acknowledgments}

This work was supported by the Korea University Grant.

\section{REFERENCES}

1. Faderl S, Talpaz M, Estrov Z, O’Brien S, Kurzrock R, Kantarjian HM. The biology of chronic myeloid leukemia. N Engl J Med 1999;341:164-172.

2. Buchdunger E, Zimmermann J, Mett H, et al. Inhibition of the $\mathrm{Abl}$ protein-tyrosine kinase in vitro and in vivo by a 2-phenylaminopyrimidine derivative. Cancer Res 1996;56:100-104.

3. Druker BJ, Tamura S, Buchdunger E, et al. Effects of a selective inhibitor of the Abl tyrosine kinase on the growth of Bcr-Abl positive cells. Nat Med 1996;2:561-566.

4. O'Brien SG, Guilhot F, Larson RA, et al. Imatinib compared with interferon and low-dose cytarabine for newly diagnosed chronic-phase chronic myeloid leukemia. N Engl J Med 2003;348:994-1004.

5. Deininger M, O'Brien SG, Guilhot F, et al. International randomized study of interferon vs STI571 (IRIS) 8-year follow up: sustained survival and low risk for progression or events in patients with newly diagnosed chronic myeloid leukemia in chronic phase (CML-CP) treated with imatinib. Blood 2009;114:1126.

6. Gambacorti-Passerini CB, Gunby RH, Piazza R, Galietta A, Rostagno R, Scapozza L. Molecular mechanisms of resistance to imatinib in Philadelphia-chromosome-positive leukaemias. Lancet Oncol 2003;4:75-85.

7. Karvela M, Helgason GV, Holyoake TL. Mechanisms and novel approaches in overriding tyrosine kinase inhibitor resistance in chronic myeloid leukemia. Expert Rev Anticancer Ther 2012;12:381-392.

8. Tauchi T, Ohyashiki K. Molecular mechanisms of resistance of leukemia to imatinib mesylate. Leuk Res 2004;28 Suppl 1:S39-S45.

9. Kantarjian H, Shah NP, Hochhaus A, et al. Dasatinib versus imatinib in newly diagnosed chronic-phase chronic myeloid leukemia. N Engl J Med 2010;362:2260-2270.

10. Saglio G, Kim DW, Issaragrisil S, et al. Nilotinib versus imatinib for newly diagnosed chronic myeloid leukemia.
N Engl J Med 2010;362:2251-2259.

11. Cilloni D, Saglio G. Molecular pathways: BCR-ABL. Clin Cancer Res 2012;18:930-937.

12. Choi JG, Kim JL, Park J, et al. Effects of oral iron chelator deferasirox on human malignant lymphoma cells. Korean J Hematol 2012;47:194-201.

13. Kim JL, Kang HN, Kang MH, Yoo YA, Kim JS, Choi CW. The oral iron chelator deferasirox induces apoptosis in myeloid leukemia cells by targeting caspase. Acta Haematol 2011;126:241-245.

14. Le NT, Richardson DR. The role of iron in cell cycle progression and the proliferation of neoplastic cells. Biochim Biophys Acta 2002;1603:31-46.

15. Kalinowski DS, Richardson DR. The evolution of iron chelators for the treatment of iron overload disease and cancer. Pharmacol Rev 2005;57:547-583.

16. Buss JL, Greene BT, Turner J, Torti FM, Torti SV. Iron chelators in cancer chemotherapy. Curr Top Med Chem 2004;4:1623-1635.

17. List AF, Baer MR, Steensma DP, et al. Deferasirox reduces serum ferritin and labile plasma iron in RBC transfusion-dependent patients with myelodysplastic syndrome. J Clin Oncol 2012;30:2134-2139.

18. Fukushima T, Kawabata H, Nakamura T, et al. Iron chelation therapy with deferasirox induced complete remission in a patient with chemotherapy-resistant acute monocytic leukemia. Anticancer Res 2011;31:1741-1744.

19. Messa E, Carturan S, Maffe C, et al. Deferasirox is a powerful NF-kappaB inhibitor in myelodysplastic cells and in leukemia cell lines acting independently from cell iron deprivation by chelation and reactive oxygen species scavenging. Haematologica 2010;95:1308-1316.

20. Bedford MR, Ford SJ, Horniblow RD, Iqbal TH, Tselepis C. Iron chelation in the treatment of cancer: a new role for deferasirox? J Clin Pharmacol 2013;53:885-891.

21. Breccia M, Alimena G. Efficacy and safety of deferasirox in myelodysplastic syndromes. Ann Hematol 2013;92:863870.

22. Song S, Christova T, Perusini S, et al. Wnt inhibitor screen reveals iron dependence of $\beta$-catenin signaling in cancers. Cancer Res 2011;71:7628-7639.

23. Chou TC, Talalay P. Quantitative analysis of dose-effect relationships: the combined effects of multiple drugs or enzyme inhibitors. Adv Enzyme Regul 1984;22:27-55.

24. Chou TC. Drug combination studies and their synergy quantification using the Chou-Talalay method. Cancer 
Res 2010;70:440-446.

25. Keutgens A, Robert I, Viatour P, Chariot A. Deregulated NF-kappaB activity in haematological malignancies. Biochem Pharmacol 2006;72:1069-1080.

26. Gasparini C, Celeghini C, Monasta L, Zauli G. NF- $\mathrm{B}$ pathways in hematological malignancies. Cell Mol Life Sci 2014;71:2083-2102.

27. Reuther JY, Reuther GW, Cortez D, Pendergast AM, Baldwin AS Jr. A requirement for NF-kappaB activation in Bcr-Abl-mediated transformation. Genes Dev 1998;12:968-981.

28. Cilloni D, Messa F, Arruga F, et al. The NF-kappaB pathway blockade by the IKK inhibitor PS1145 can overcome imatinib resistance. Leukemia 2006;20:61-67.

29. Lounnas N, Frelin C, Gonthier N, et al. NF-kappaB inhibition triggers death of imatinib-sensitive and imatinib-resistant chronic myeloid leukemia cells including
T315I Bcr-Abl mutants. Int J Cancer 2009;125:308-317.

30. Wei YL, Liang Y, Xu L, Zhao XY. The antiproliferation effect of berbamine on $\mathrm{k}_{5} 62$ resistant cells by inhibiting NF-kappaB pathway. Anat Rec (Hoboken) 2009;292:945950.

31. Hu Y, Swerdlow S, Duffy TM, Weinmann R, Lee FY, Li S. Targeting multiple kinase pathways in leukemic progenitors and stem cells is essential for improved treatment of Ph+ leukemia in mice. Proc Natl Acad Sci U S A 2006;103:16870-16875.

32. $\mathrm{Hu} \mathrm{Y}$, Chen Y, Douglas L, Li S. beta-Catenin is essential for survival of leukemic stem cells insensitive to kinase inhibition in mice with BCR-ABL-induced chronic myeloid leukemia. Leukemia 2009;23:109-116.

33. Coluccia AM, Vacca A, Dunach M, et al. Bcr-Abl stabilizes beta-catenin in chronic myeloid leukemia through its tyrosine phosphorylation. EMBO J 2007;26:1456-1466. 